\title{
Chronic persistent hepatitis: hepatitis B virus markers and histological follow-up
}

\author{
R. G. CHADWICK, J. GALIZZI, JR, J. HEATHCOTE, T. LYSSIOTIS, B. J. COHEN, \\ P. J. SCHEUER, AND S. SHERLOCK
}

From the Departments of Medicine and Histopathology, Royal Free Hospital, Hampstead, London, and the Virus Reference Laboratory, Central Public Health Laboratory, Colindale, London

SUMMARY Twenty-six untreated patients with chronic persistent hepatitis were followed prospectively for one to 17 years (mean 5.6 years). The patients developed no clinical features of chronic liver disease. Raised serum transaminase levels were usually, but not consistently, the only biochemical abnormality; gamma globulin values were normal. Serum markers of past or present hepatitis B infection were found initially in 14 patients: another two developed markers during their follow-up. Nine patients progressed to a mild or moderate chronic active hepatitis as shown by serial needle liver biopsies but there was no evidence of cirrhosis. This progression was not associated with any clinical or biochemical deterioration. Seven of these patients had presented with insidious symptoms, seven had serum markers of hepatitis B infection, and the four who were $\mathrm{HBs} A g$ positive had relatively lower serum HBsAg concentrations than did those patients who continued with chronic persistent hepatitis.

Chronic hepatitis is defined as inflammation of the liver continuing without improvement for at least six months (Leevy et al., 1976). On histological grounds it can be divided broadly into chronic active hepatitis characterised by piecemeal necrosis and intralobular fibrosis, and chronic persistent hepatitis in which there is round cell infiltration with some expansion of the portal areas, but no piecemeal necrosis or intralobular fibrosis. Between chronic active hepatitis and chronic persistent hepatitis, there lies a continuum of histological abnormality which includes 'mild' chronic active hepatitis and 'less' active hepatitis (De Groote et al., 1968, 1976; Scheuer, 1977).

Untreated chronic active hepatitis is generally thought to progress to cirrhosis. The situation with chronic persistent hepatitis is less clear and published reports suggest that the disease may either remain completely benign, or progress to chronic active hepatitis and cirrhosis (Vido et al., 1969; Van Waes et al., 1974; Dietrichson, 1975).

In this study, 26 patients with chronic persistent hepatitis have been followed prospectively for up to 17 ycars. The clinical course, biochemical tests, and serial liver biopsies have been assessed. It has also been possible with serological markers to detect which patients have past or present hepatitis B

Received for publication 19 December 1978 infection, and whether this is reflected in the course of the disease.

\section{Methods}

\section{SELECTION OF PATIENTS}

Histological sections of liver biopsies taken over the previous 15 years were reviewed. Those that had been classified as chronic persistent hepatitis, borderline chronic persistent/chronic active hepatitis, chronic lobular hepatitis, and 'minimal changes' were re-examined by two of the authors (J.G. and P.J.S.). Of 107 initially selected, 81 were not included for one or more of the following reasons: (1) initial diagnosis made less than six months after an attack of acute hepatitis; (2) inadequate liver biopsy (less than three portal tracts) or no follow-up biopsy available; (3) immunosuppressive therapy before or during the period of review.

\section{LABORATORY TESTS}

Each patient had blood taken for haematological indices, platelet count, prothrombin time, bilirubin, asparate transaminase (AsT), alkaline phosphatase, albumin, and globulin determination. Immunoglobulins and $\alpha_{1}$ antitrypsin concentrations were measured by radial immunodiffusion (Tri-partigen and $\mathrm{M}$ partigen plates, Hoechst Pharmaceuticals). HBsAg was measured by reversed passive haemagglutination 
(Hepatest, Wellcome Laboratories) using serum neat, and at 1 in 10 , and 1 in 100 dilutions; weakly positive results were checked by radioimmunoassay (Ausria II-125, Abbott Laboratories). HBs antibody was measured by radioimmunoassay (Ausab, Abbott Laboratories). HBc antibody was determined by counter immunoelectrophoresis (CIEP) and complement fixation (Cohen and Cossart, 1977). Weakly positive CIEP results in anti-complementary sera were checked by electron-microscopic examination of the electrophoretic gel containing the precipitin line, to search for immune complexes. HBe antigen and antibody were measured by immunodiffusion (Magnius and Espmark, 1972). Nuclear, mitochondrial, and smooth muscle antibodies were demonstrated by immunofluorescence (Weller and Coons, 1954). Percutaneous liver biopsies were taken with a Menghini needle. Sections were stained with haematoxylin and eosin, by Gordon and Sweet's method of silver impregnation for demonstration of reticulin fibres, by the periodic acid-Schiff method after digestion with diastase, by a modification of Perls' Prussian blue method for demonstration of iron (Scheuer, 1973) and by the immunoperoxidase method for demonstration of HBsAg (Burns, 1975). Stained sections of liver biopsies taken at other hospitals were also reviewed. Biopsies showing less than three portal tracts in each section were generally considered to be too small for accurate diagnosis.

\section{Results}

The 26 patients ( 23 men and three women) had a mean age of 36 years (Fig. 1). Thirteen were North European, seven were from Mediterranean countries, three from the Indian subcontinent, and one each from Ethiopia, Brazil, and Iran. The British patients were professional or 'white-collar' workers; those from overseas were all professional people, and included four surgeons working in hepatitis B endemic areas. None had received corticosteroid therapy either before diagnosis or during the followup period.

Routine haematological tests and prothrombin times were always normal. Serum bilirubin, alkaline phosphatase, and gamma globulin levels were generally normal by the time that the diagnosis of chronic persistent hepatitis was established. AsT levels fluctuated but were generally below four times the upper limit of normal. Immunoglobulins G, A and $M$, and $\alpha_{1}$ antitrypsin concentrations were normal.

Chronic persistent hepatitis was demonstrated by needle liver biopsy (Table 1). The histological criteria were those laid down by De Groote $e t$ al. (1968): (chronic inflammatory infiltration, mostly portal, with preserved lobular architecture, and little or no fibrosis. Piecemeal necrosis is absent or slight. Features of acute hepatitis may be super-

Table 1 Histological findings of 26 patients at time of diagnosis of chronic persistent hepatitis

\begin{tabular}{|c|c|c|}
\hline \multirow[t]{2}{*}{ Histological abnormality } & \multicolumn{2}{|c|}{ Patients } \\
\hline & (no.) & $(\%)$ \\
\hline \multicolumn{3}{|l|}{ Portal tract abnormalities } \\
\hline $\begin{array}{l}\text { Enlargement } \\
\text { Infiltration }\end{array}$ & 26 & $\begin{array}{l}100 \\
100\end{array}$ \\
\hline With plasma cells & 25 & 96 \\
\hline With eosinophils & 11 & 42 \\
\hline With neutrophils & 7 & 27 \\
\hline Spillover of inflammatory cells & 10 & 38 \\
\hline Bile duct proliferation & 1 & 4 \\
\hline Bile duct damage & 2 & 8 \\
\hline Lymphoid aggregates & 2 & 8 \\
\hline \multicolumn{3}{|l|}{ Necrosis } \\
\hline Focal & 26 & 100 \\
\hline Portal-portal bridging & 6 & 23 \\
\hline Central-portal bridging & 1 & 4 \\
\hline \multicolumn{3}{|l|}{ Structural changes (in 23 biopsies) } \\
\hline Portal fibrosis & 16 & 70 \\
\hline Septum formation & 10 & 43 \\
\hline Intralobular fibrosis & 1 & 4 \\
\hline Fibrosis at edge of biopsy & 4 & 17 \\
\hline Distortion of lobular architecture & 6 & 26 \\
\hline Nodules & $\mathbf{0}$ & $\mathbf{0}$ \\
\hline \multicolumn{3}{|l|}{ Other lobular changes } \\
\hline Focal inflammation & 24 & 92 \\
\hline Diffuse sinusoidal infiltration & 22 & 85 \\
\hline Pericentral inflammation & 20 & 77 \\
\hline Diffuse Kupffer cell hypertrophy & 26 & 100 \\
\hline Liver cell swelling in central areas & 13 & 50 \\
\hline Fat & 14 & 54 \\
\hline HBsAg positive cells & 8 & 31 \\
\hline Liver cells siderosis & 6 & 23 \\
\hline Reticuloendothelial siderosis & 1 & 4 \\
\hline Cholestasis & 1 & 4 \\
\hline$a_{1}$ antitrypsin bodies & $\mathbf{0}$ & $\mathbf{0}$ \\
\hline
\end{tabular}

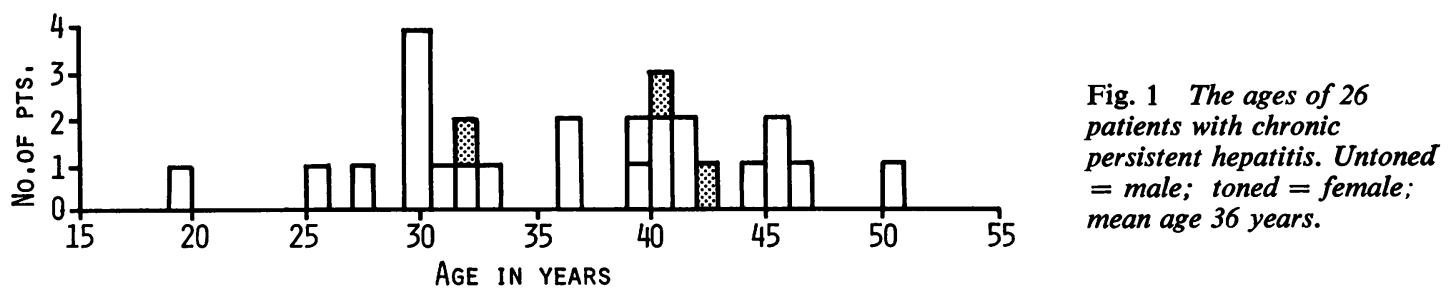


imposed). In addition to the portal changes, lobular alterations were often found, some of them presumably the result of acute hepatitis during the previous months. Focal necrosis was universal, but usually very mild. Portal tracts were linked in a few cases, but central-to-portal bridging was detected in only one biopsy. In 10 patients the diagnosis was made at least six months after an illness typical of acute icteric viral hepatitis, and in one there was an episode of severe but transient hepatic failure. Six of these showed markers of hepatitis B. Fourteen patients presented with insidious symptoms, usually fatigue or malaise which had been present for at least six months, during which time persistently abnormal liver function tests had been recorded. Two asymptomatic patients were blood donors found to be HBsAg positive on routine screening. Ten of these patients showed markers of hepatitis B infection. Thus a total of 16 of the 26 subjects showed one or more serological markers of past or present hepatitis $B$ infection. Ten patients were both HBsAg and $\mathrm{HBc}$ antibody positive. Two of these showed $\mathrm{HBe}$ antigen but not $\mathrm{HBe}$ antibody. Two were $\mathrm{HBs}$ - and $\mathrm{HBc}$-antibody positive, while two showed HBs antibody alone. Two others developed
HBs antibody during the follow-up period. In the remaining 10 patients, no aetiological factors could be found. In particular, significant levels of serum nuclear, smooth muscle, and mitochondrial antibodies were not detected. None was an alcoholic. None was taking any hepatotoxic medication and none was abusing drugs.

\section{FOLLOW-UP}

The 26 subjects were followed up for one to 17 years (mean 5.6 years), during which time a total of 68 liver biopsies were taken (Fig. 2). Symptoms when present did not change, and in general all patients remained well and at work. None developed signs of chronic liver disease, and, in particular, splenomegaly, fluid retention, and spider naevi were not seen. Serum transaminase levels fluctuated; bilirubin, alkaline phosphatase and gammaglobulin levels remained normal.

In 16 patients serial biopsies showed continuing chronic persistent hepatitis indicating that the portal inflammation seen in the initial biopsies was not merely the residual inflammation of a normally resolving acute hepatitis. One showed apparent healing. Nine developed histological features of

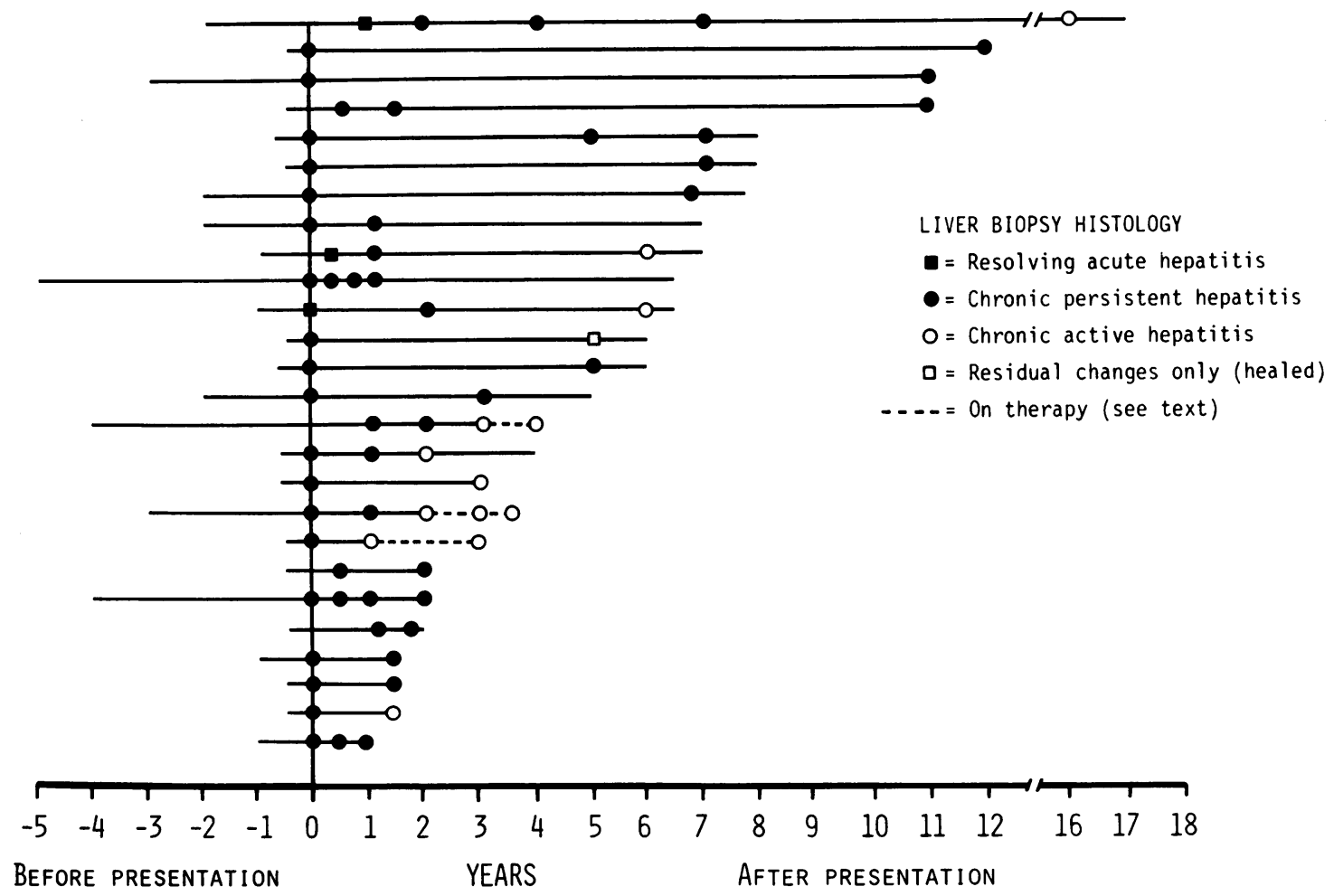

Fig. 2 Liver biopsies and lengths of observation periods of 26 patients with chronic persistent hepatitis. 
chronic active hepatitis. In seven, this was shown by mild piecemeal necrosis and lymphocytic infiltration, the appearances being on the borderline with chronic persistent hepatitis. Two patients showed somewhat more severe histological abnormalities of similar type (chronic active hepatitis of moderate severity). Cirrhosis did not appear to have developed in any patient. The four patients with biopsy evidence of lymphoid follicles or bile duct damage, lesions which are said to be markers of a poorer prognosis (Popper and Schaffner, 1976), all continued as chronic persistent hepatitis.

The development of chronic active hepatitis seemed related to the mode of onset, for seven of the 14 presenting insidiously showed progression to chronic active hepatitis, whereas only one of 10 presenting with an acute illness progressed (Table 2). Five of eight serum-HBsAg positive patients, and seven of 16 patients with one or more serum markers of hepatic B infection developed chronic active liver disease, whereas only two of 10 of those with no markers progressed.

Table 2 Association of clinical presentation and histological outcome with presence or absence of hepatitis $B$ markers in serum of 26 patients with chronic persistent hepatitis

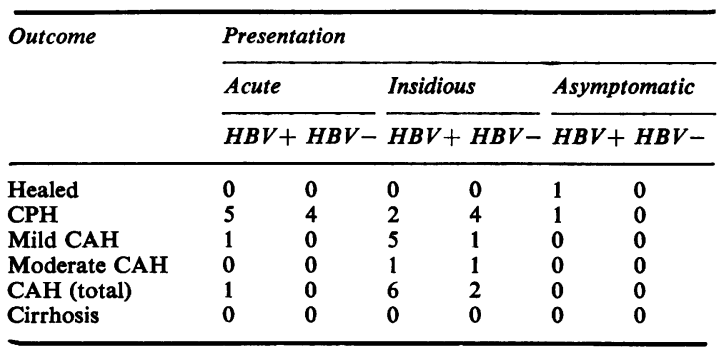

The HBsAg titres of serum taken from patients at the time of initial diagnosis of chronic persistent hepatitis tended to be higher in those patients in whom the disease persisted, and lower in those who progressed to $\mathrm{CAH}$; the $\mathrm{HBc}$ antibody titres of the same serum specimens did not appear to be of similar prognostic value (Fig. 3). Only two of the HBsAg positive patients had $\mathrm{HBe}$ antigenaemia; both developed chronic active disease. No patient had detectable $\mathrm{HBe}$ antibody.

The nine patients who developed chronic active hepatitis have been followed up for one to three years (mean one-and-a-half years) since the histological progression of the disease was first noted. The clinical features have remained unchanged. The two patients with more pronounced histological changes have been treated with prednisolone; one of
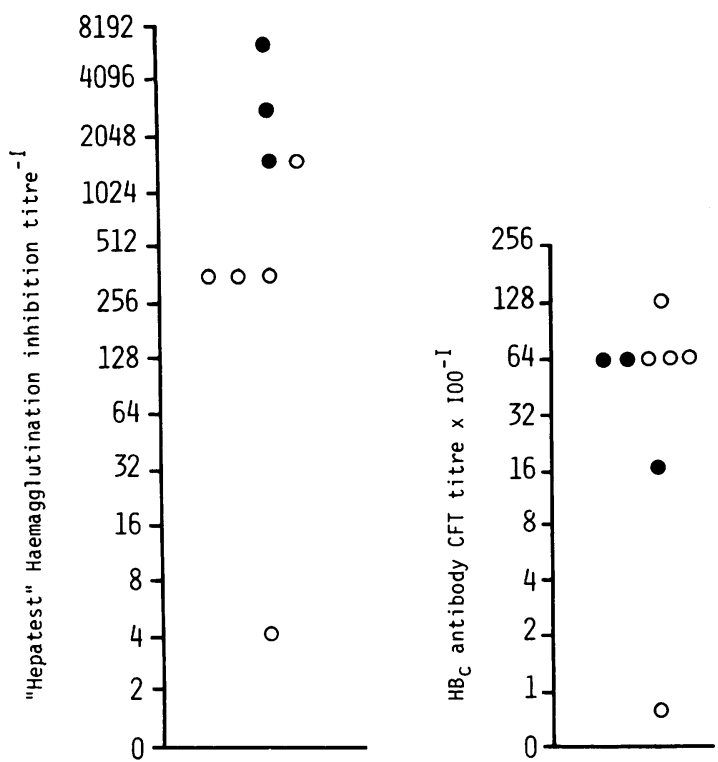

Fig. 3 Initial Hepatest HBsAg titres, and HBc antibody $C F$ titres of eight patients with chronic persistent hepatitis. $\bullet$ : continued as $\mathrm{CPH}$; $\bigcirc$ : developed $\mathrm{CAH}$.

the mild chronic active group has received immunostimulant and antiviral therapy. The former two patients have each been rebiopsied after one year, the latter has had two additional biopsies after six months and one year. No further histological change has yet been noted.

\section{Discussion}

This study confirms many of the findings of Becker and co-workers (1970), one of whose patients is included in this survey. Patients with chronic persistent hepatitis are usually male and present in their fourth decade. The illness may start acutely or insidiously, although by the time the diagnosis is established the patients are usually asymptomatic. Signs of chronic liver disease are absent. Serum bilirubin, alkaline phosphatase, and gammaglobulin levels are usually normal and transaminase values fluctuate. The patients of Becker and his colleagues were all $\mathrm{HBsAg}$ negative, but were studied at a time when the methods of detecting $\mathrm{HBsAg}$ were crude, and other markers related to the hepatitis $B$ virus were not yet discovered. The present study was therefore particularly concerned with the relationship of hepatitis B to chronic persistent hepatitis, and whether patients with hepatitis B markers followed a different course from those in whom no aetiology was evident. 
The ten $\mathrm{HBsAg}$ positive patients were all $\mathrm{HBc}$ antibody positive, and had histologically demonstrable HBsAg in the liver. It seems reasonable to conclude that this group had continuing hepatitis B infection. Two HBsAg negative patients had both HBs- and HBc-antibodies, implying contact with both surface and core components of the hepatitis B virus. This must represent previous though relatively recent hepatitis $\mathrm{B}$ infection, as $\mathrm{HBc}$ antibody usually disappears from the serum earlier than does HBs antibody. The implications of the presence of HBs antibody alone are less clear. This antibody can be found in up to $30 \%$ of normal population, and biopsies from 17 of $101 \mathrm{HBs}$ antibody positive patients showed abnormalities in eight, of which four had CPH (Boyes et al., 1974; Fairclough et al., 1974). However, $\mathrm{HBc}$ antibody was not measured, and the two series were not controlled, no allowance being made for the possible occurrence of abnormal liver biopsy findings in HBs-antibody negative 'normal' populations.

The aetiology in those patients who did not have hepatitis B markers remained unknown.

Nine of the 26 patients appeared to progress to chronic active liver disease, but it should be stressed that, in most instances, activity was minimal, and that the diagnosis of chronic active hepatitis includes a range of histological lesions of widely differing severity. It is possible that some of these nine patients had CAH at the time of the initial biopsy and that the correct diagnosis was not made then because of sampling error. This sampling effect was minimised in this series by excluding patients whose liver biopsies contained less than three portal tracts in each section. Other difficulties of histological interpretation have been detailed by Scheuer (1977). Spillover of inflammatory cells from the portal tracts may mimic piecemeal necrosis and may make differentiation from chronic active hepatitis difficult (Bianchi et al., 1977). However, piecemeal necrosis was not considered to be present in any of the biopsies diagnosed as chronic persistent hepatitis. Immunosuppressive therapy may change chronic active hepatitis into an apparent chronic persistent hepatitis (Bagenstoss et al., 1972). This may revert to the original chronic active hepatitis as soon as therapy is stopped. None of the patients reported had received corticosteroids or azathioprine. The histological appearances of chronic persistent hepatitis are not specific, and it can be mimicked by non-specific reactive hepatitis, residual acute hepatitis, early primary biliary cirrhosis, and early lymphomatous infiltration. As far as possible these causes have been excluded. The progression to chronic active hepatitis was not associated with any change in symptoms, or with the development of signs of chronic liver disease, and biochemical tests remained essentially unchanged.

This study suggests that chronic persistent hepatitis presenting with symptoms of insidious onset is more likely to progress to chronic active liver disease, than when the presentation is an acute icteric illness. The reason for this difference remains obscure. Also unexplained is the observation that progression appears more likely in both $\mathrm{HBsAg}$ positive subjects and in patients who, though HBsAg-negative, have demonstrable serum antibodies to $\mathrm{HBcAg}$ and/or HBsAg.

Hoofnagle and co-workers suggested that high serum titres of $\mathrm{HBc}$ antibody reflect continuing viral replication (Hoofnagle et al., 1975). Kojima et al. (1977) also reported that the highest serum $\mathrm{HBc}$ antibody titres were associated with HBsAg demonstrable by immunofluorescence in liver biopsies. When $\mathrm{HBc}$ antibody titres were lower, the viral antigens could not be demonstrated in the liver biopsies. Similarly, in the HBsAg positive patients in our group, higher $\mathrm{HBc}$ antibody titres might have been correlated with greater likelihood of progressive liver disease. This correlation was not observed: however, the numbers of patients were small (Fig. 3).

HBe antigen has also been promoted as a useful prognostic pointer (Trepo et al., 1976). This antigen was found in the sera of two of eight HBsAg positive patients from whom blood was available; both progressed to chronic active liver disease. The proportion of cases in whom this antigen is demonstrable may increase when more sensitive techniques for $\mathrm{HBeAg}$ detection such as radioimmunoassay become more widely available (Mushahwar et al., 1978).

Dudley and co-workers (1971) showed that the serum HBsAg concentration in chronic persistent hepatitis patients tended to be higher than in those with chronic active hepatitis or cirrhosis. Our chronic persistent hepatitis patients with higher HBsAg concentrations have tended to continue as such, whereas those with lower concentrations have apparently progressed to chronic active hepatitis. This may reflect sampling error in the latter group but nevertheless still appears to be a useful prognostic marker, and further observations upon a larger group of $\mathrm{HBsAg}$ positive patients are being made to confirm this impression.

Overall, chronic persistent hepatitis should still be considered as a benign condition. A minority of patients appear to develop histological features of relatively mild chronic active hepatitis. Clinical presentation and hepatitis-B serum markers may be useful prognostic pointers but liver biopsy remains the only certain way of identifying this apparent progression. 


\section{References}

Bagenstoss, A. H., Soloway, R. D., Summerskill, W. H. J., Eleveback, L. R., and Schoenfield, L. J. (1972). Chronic active liver disease. The range of histologic lesions, their response to treatment, and evolution. Human Pathology, 3 , 183-198.

Becker, M. D., Scheuer, P. J., Baptista, A., and Sherlock, S. (1970). Prognosis of chronic persistent hepatitis. Lancet, 1 , 53-57.

Bianchi, L., De Groote, J., Desmet, V. J., Gedigk, P., Korb, G., Popper, H., Poulsen, H., Scheuer, P. J., Schmid, M., Thaler, H., and Wepler, W. (1977). Acute and chronic hepatitis revisited. Lancet, 2, 914-919.

Boyes, B. E., Woolf, I. L., Whittaker, J. S., Tapp, E., Jones, D. M., Renton, P. H., Stratton, F., McSween, R., and Dymock, I. W. (1974). Liver disease in healthy blood donors associated with the presence of hepatitis B antibody (Abstract). Gut, 15, 341 .

Burns, J. (1975). Immunoperoxidase localisation of hepatitis $B$ antigen (HB) in formalin-paraffin processed liver tissue. Histochemistry, 44, 133-135.

Cohen, B. J., and Cossart, Y. E. (1977). Application of a screening test for antibody to hepatitis B core antigen. Journal of Clinical Pathology, 30, 709-713.

De Groote, J., Desmet, V. J., Gedigk, P., Korb, G., Popper, H., Poulsen, H., Scheuer, P. J., Schmid, M., Thaler, H., Uehlinger, E., and Wepler, W. (1968). A classification of chronic hepatitis. Lancet, 2, 626-628.

De Groote, J., Fevery, J., Verbrugge, J., Desmet, V., and Vandenbroucke, J. (1976). Less active hepatitis. In Chronic Hepatitis (International Symposium on Problems of Chronic Hepatitis, Montecatini, 1975). Edited by P. Gentilini et al. Karger: Basel.

Dietrichson, O. (1975). Chronic persistent hepatitis. A clinical, serological and prognostic study. Scandinavian Journal of Gastroenterology, 10, 249-255.

Dudley, F. J., Fox, R. A., and Sherlock, S. (1971). Relationship of hepatitis-associated antigen (HAA) to acute and chronic liver injury. Lancet, 2, 1-3.

Fairclough, E. D., Slavin, G., Willis, E., Cleghorn, T. P., Denman, M., and Levi, A. J. (1974). Studies on carriers of Australia antibody (Abstract). Gut, 15, 341 .

Hoofnagle, J. H., Gerety, R. J., and Barker, L. F. (1975).
Antibody to hepatitis B core antigen. American Journal of Medical Science, 270, 179-187.

Kojima, M., Udo, K., Takahashi, Y., Yoshizawa, H., Tsuda, F., Itoh, Y., Miyakawa, Y., and Mayumi, M. (1977). Correlation between titer of antibody to hepatitis B core antigen and presence of viral antigens in the liver. Gastroenterology, 73, 664-667.

Leevy, C. M., Popper, H., and Sherlock, S. (1976). Diseases of the Liver and Biliary Tract: Standardization of Nomenclature, Diagnostic Criteria and Diagnostic Methodology. (Fogarty International Center Proceedings No. 22. DHEW Publication No. (NIH) 76-725.) U.S. Government Printing Office: Washington, D.C.

Magnius, L. O., and Espmark, J. A. (1972). New specificities in Australia antigen positive sera distinct from the Le Bouvier determinants. Journal of Immunology, 109, 11171121.

Mushahwar, I. K., Overby, L. R., Frosner, G., Deinhardt, F., and Ling, C. M. (1978). Prevalence of hepatitis Be antigen and its antibody as detected by radioimmunoassays. Journal of Medical Virology, 2, 77-87.

Popper, H., and Schaffner, F. (1976). Progress in Liver Diseases, vol 5, p. 540. Grune and Stratton: New York.

Scheuer, P. J. (1973). Liver Biopsy Interpretation, 2nd edn. Baillière, Tindall: London.

Scheuer, P. J. (1977). Chronic hepatitis: a problem for the pathologist. Histopathology, 1, 5-19.

Trepo, C. G., Magnius, L. O., Schaeffer, R. A., and Prince, A. M. (1976). Detection of e antigen and antibody: correlations with hepatitis B surface and hepatitis B core antigens, liver disease and outcome in hepatitis B infections. Gastroenterology, 71, 804-808.

Vido, I., Selmair, E., Wildhirt, E., and Ortmans, H. (1969). Zur Prognose der chronischen Hepatitis. 1. Formen und Entwicklungsstadien. Deutsche Medizinische Wochenschrift, 94, 2215-2220.

Weller, T. H., and Coons, A. H. (1954). Fluorescent antibody $r$ studies with agents of varicella and Herpes zoster propagated in vitro. Proceedings of the Society for Experimental: Biology and Medicine, 86, 789-794.

Van Waes, L., Segers, J., Van Egmond, J., Van Nimmen, Li., Barbier, F., Wieme, R., and Demeulenaere, L. (1974). Chronic liver disease and hepatitis B antigen: a prospective. study. British Medical Journal, 3, 444-446. 